\title{
EVALUASI PERTUMBUHAN AREN (Arenga pinnata (Wurmb)) DI LAHAN PASCA TAMBANG PT BERAU COAL KALIMANTAN TIMUR
}

\section{(Growth Evaluation of Sugar Palm (Arenga pinnata (Wurmb)) on Post-Mining Land at PT Berau Coal Kalimantan Timur)}

\author{
ISTIQOMAH SAMAL ${ }^{1 *)}$, IRDIKA MANSUR ${ }^{1)}$, AHMAD JUNAEDI $^{2)}$ DAN HIFZIL KIRMI $^{3)}$ \\ 1) Departemen Silvikultur, Fakultas Kehutanan, Institut Pertanian Bogor, Kampus Darmaga, Bogor, Indonesia 16680 \\ 2) Departemen Agronomi dan Holtikultura, Fakultas Pertanian, Institut Pertanian Bogor, Kampus Darmaga, Bogor \\ Indonesia 16680 \\ 3) Departemen Lingkungan Hidup PT Berau Coal Kabupaten Berau Kalimantan Timur 4, Indonesia 33172
}

*Email: istiqamahsamal@gmail.com

Diterima 03 Januari 2020 / Disetujui 08 Mei 2020

\begin{abstract}
Mining activities have always resulted in soil degradation, biodiversity loss and ecosystem disturbance, which required reclamation and revegetation activities. Revegetation is an effort to restore the damaged vegetation from mining activities. PT Berau Coal has conducted revegetation activities using the local palm sugar plant (Arenga pinnata). An evaluation was necessary to determine the level of success of sugar palm growth and status of the revegetation. Data on the growth of the sugar palms was collected using Systematic Sampling with Random Start method at several locations, i.e., IPD D2, IPD C3.1 and 2, IPD K and IPD 6. The growth indicators observed, consisted of height, diameter, number of leaves, survival percentage and percentage of healthy plants. The results showed that the survival rate of the planted sugar palms varied across locations, with the lowest of $19.35 \%$ at C3.1 IPD and the highest at 87.1\% at the D2 IPD, while the lowest healthy palms was found in C3.2 IPD with a health percentage of $26.32 \%$ and the highest was found on IPD D6 and IPD C3.1 with $100 \%$ healthy palms.. The main factors contributing to the failure of survival and growth of the sugar palms were soil tillage, shade, weeds, pest and disease attacks.
\end{abstract}

Keywords: evaluation, mining, revegetation, sugar palm

\section{ABSTRAK}

Kegiatan tambang selalu menimbulkan dampak negatif berupa rusaknya tanah, hilangnya vegetasi dan satwa hingga mengganggu ekosistem, oleh karena itu perlu dilakukan reklamasi dan revegetasi. Revegetasi adalah upaya untuk memperbaiki dan mengembalikan vegetasi yang rusak akibat kegiatan tambang. PT Berau Coal telah melakukan revegetasi dengan menggunakan tanaman lokal yaitu aren (Arenga pinnata). Evaluasi perlu dilakukan untuk mengetahui pertumbuhan tanaman dan status keberhasilan upaya revegetasi tanaman aren yang dilakukan oleh PT Berau Coal. Metode pengambilan data keragaan pertumbuhan aren dilakukan dengan metode Systematic Sampling with Random Start pada lokasi IPD D2, IPD C3.1 dan 2, IPD K dan IPD 6. Data keragaan yang diamati berupa data tinggi, diameter, jumlah daun serta persen hidup dan persen kesehatan tanaman aren. Hasil penelitian menunjukkan bahwa persen hidup aren di areal pasca tambang bervariasi, antara paling rendah $19,35 \%$ di lokasi IPD C3.1 dan paling tinggi 87,1\% di lokasi IPD D2, sedangkan persen kesehatan paling rendah ditemukan pada lokasi IPD C3.2 yaitu 26,32\% dan tertinggi pada lokasi IPD D6 dan IPD C3.1 yaitu 100\%. Faktor utama penyebab kegagalan kelangsungan hidup dan pertumbuhan aren yaitu kesalahan pengolahan tanah, naungan, gulma dan serangan hama dan penyakit.

Kata kunci: evaluasi, pertambangan, revegetasi, tanaman aren.

\section{PENDAHULUAN}

Indonesia merupakan negara yang memiliki sumberdaya alam berupa bahan tambang yang melimpah, seperti batu bara, nikel, emas, bauksit, tembaga, dan lain sebagainya, sehingga selama lebih dari 30 tahun, bidang pertambangan merupakan kontributor terbesar dalam pembangunan ekonomi Indonesia (Agus et al. 2014). Produksi mineral tambang dan batu bara di Indonesia, selalu mengalami peningkatan setiap tahunnya dilihat dari jumlah produksi batu bara pada tahun 2016 sebesar 456,17 juta ton yang meningkat hingga 565,81 juta ton pada tahun 2019 (Kementerian ESDM 2019).
Kegiatan usaha pertambangan dapat berdampak positif maupun negatif. Dampak positif yang ditimbulkan di antaranya adalah memberikan pemasukan besar bagi negara dalam bentuk royalti, Penerimaan Negara Bukan Pajak (PNBP) dan lain-lain, adapun dampak negatifnya adalah menurunnya tingkat kesuburan tanah, $\mathrm{pH}$ rendah bahkan sangat rendah, pemadatan tanah yang berdampak pada rendahnya kemampuan menahan air (low water holding capacity), pasokan unsur hara pada tanaman tidak memadai, erosi, dan terpaparnya batuan yang mengandung sulfida dengan air dan oksigen yang mengakibatkan adanya Air Asam Tambang sehingga menyebabkan terganggunya ekosistem lingkungan (Widyati 2009; Kumar 2013; Puspanti 2013; Herlina et 
al. 2014). Forest Watch Indonesia (2011) menghitung laju deforestasi dalam rentang tahun 2000-2009 seluas 15,15 juta hektar dan salah satu faktor penyebabnya adalah pertambangan. Berdasarkan data Ditjen Planologi, penggunaan kawasan hutan untuk pertambangan di seluruh Indonesia mencapai 48,9 juta ha sedangkan izin Pinjam Pakai Kawasan Hutan (IPPKH) yang di berikan pemerintah hanya seluas 0,46 juta ha (Nanggara et al. 2018) Hal ini berdampak pada beroperasinya kegiatan pertambangan yang melanggar aturan kehutanan dan prinsip praktik pertambangan yang baik (good mining practices). Kegiatan reklamasi lahan bekas tambang dilakukan untuk mengatasi kerusakan tersebut. Keberhasilan reklamasi membutuhkan pengetahuan dasar tentang lingkungan di lahan pasca tambang maupun sebelum tambang dan proses suksesinya (Kurniawan et al. 2013).

Reklamasi didefinisikan sebagai kegiatan yang dilakukan sepanjang tahapan usaha pertambangan untuk menata, memulihkan, dan memperbaiki kualitas lingkungan dan ekosistem agar dapat berfungsi kembali sesuai peruntukannya (Permen ESDM 2018). PT Berau Coal merupakan salah satu perusahaan tambang batu bara yang terletak di Kabupaten Berau, Kalimantan Timur yang telah memiliki persetujuan penggunaan kawasan hutan produksi sebagaimana ditetapkan dalam Keputusan Menteri Kehutanan Nomor 554/MenhutII/1993 pada tanggal 8 Maret 1993, dan perjanjian pinjam pakai kawasan hutan dengan Departemen Kehutanan dan Perkebunan. PT Berau Coal memiliki tiga lokasi penambangan yaitu Site Lati, Sambarata dan Binungan. Selain dilakukan aktivitas pertambangan, pada ketiga lokasi tersebut juga telah dilakukan kegiatan reklamasi lahan pasca tambang. Jenis yang digunakan untuk kegiatan revegetasi adalah tanaman aren (Arenga pinnata).

Tanaman aren merupakan tanaman lokal yang banyak dikembangkan oleh masyarakat Kalimantan Timur seperti di wilayah Samarinda, Bontang, Paser, Kutai Kartanegara, Kutai Timur, dan Kutai Barat, dengan luas total 882 ha (Disbun Prov Kaltim 2018). Tanaman aren merupakan tanaman yang seluruh bagiannya dapat dimanfaatkan: niranya dapat dijadikan gula, cuka, alkohol dan sumber energi bioethanol, buahnya (kolangkaling) dapat dijadikan bahan campuran minuman dan akarnya mampu mengurangi laju erosi serta dapat menjadi tanaman pengayaan di lahan kritis (Mariati 2013; Harahap 2017). Saat ini, aren merupakan salah satu tanaman lokal yang dijadikan tanaman pengayaan di lahan pasca tambang PT Berau Coal dan telah ditanam seluas 7 Ha. Berdasarkan latar belakang tersebut, tujuan penelitian ini adalah untuk mengevaluasi pertumbuhan dan kelangsungan hidup aren (Arenga pinnata) di lokasi penimbunan (disposal) IPD (in pit dump) D6, IPD C3.1, IPD C3.2, IPD D2 dan IPDK K.

\section{METODE PENELITIAN}

Penelitian dilaksanakan mulai bulan April sampai dengan Agustus 2019. Lokasi pengambilan data pertumbuhan aren (Arenga pinnata) dan sampel tanah dilakukan di PT Berau Coal, Site Binungan I, Berau, Kalimantan Timur (Gambar 1). Secara geografis, Site Binungan terletak antara koordinat 102 $355^{\prime} 02^{\prime \prime}$ $102^{\circ} 37^{\prime} 03^{\prime \prime}$ BT dan 03 53'35" - 03'55'37' LU dengan curah hujan tahunan di lokasi pengamatan berkisar antara $6,7 \mathrm{~mm}$ to $16,4 \mathrm{~mm} / \mathrm{bulan}$.

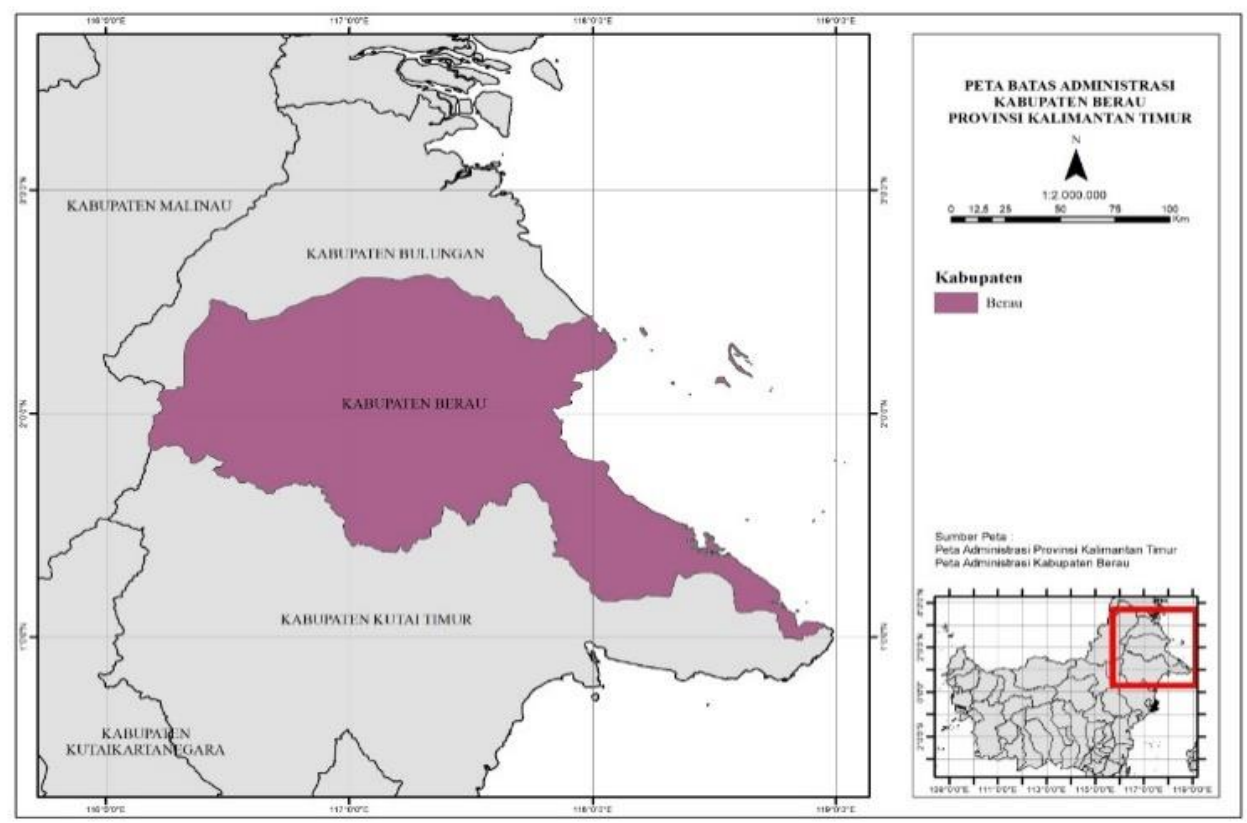

Gambar 1 Peta lokasi penelitian di PT Berau Coal Site Binungan I Berau Kalimantan Timur 
Objek penelitian adalah tanaman revegetasi di area reklamasi IPD D6, C3.1, C3.2, IPD D2 dan IPD K dengan jenis tanaman A. pinnata (aren genjah). Alat yang digunakan dalam penelitian adalah pita ukur, hagameter, tali rapia, patok, bor tanah, plastik sampel, kompas, meteran, lux meter, soil tester, tally sheet, alat tulis dan kamera.

Pembuatan plot analisis pertumbuhan aren dilakukan dengan metode purposive sampling with random start (disesuaikan dengan kondisi di lapangan) dengan membuat petak ukur persegi panjang berukuran $40 \mathrm{~m} \times 25 \mathrm{~m}(0,1 \mathrm{ha})$ atau disesuaikan dengan kondisi lapangan. Intensitas sampling yang digunakan adalah $10 \%$ dari total areal penelitian seluas 3,7 ha (Permenhut 2009), lima plot contoh pada lima lokasi yang dipilih pada areal bebas kegiatan aktivitas penambangan.

Pengambilan sampel tanah dilakukan pada plot contoh pengamatan pertumbuhan aren di masing-masing lokasi IPD D6, C3.1, C3.2, IPD D2 dan IPDK (Gambar 2). Pada setiap titik pengamatan dilakukan pengambilan sampel tanah menggunakan bor tanah dengan kedalaman (0-20) cm dan (20-40) cm sebanyak 250 gr per titik. Tanah yang diambil di setiap titik dikompositkan kemudian dimasukkan ke dalam kantong plastik dan diberi kode nama serta lokasi pengambilan tanah. Pengambilan sampel tanah utuh menggunakan ring sampel untuk mengidentifikasi sifat fisik tanah. Sampel tanah dibawa ke Laboratorium Tanah Insitut Pertanian Bogor untuk dilakukan analisis terhadap sifat fisik, kimia dan logam berat.

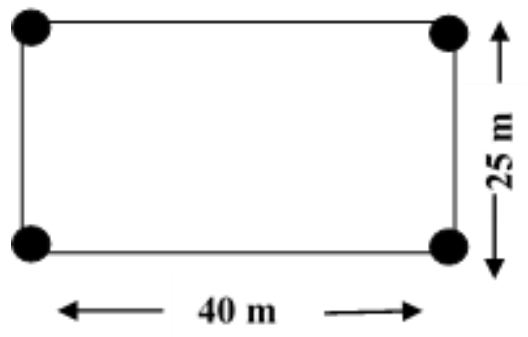

Gambar 2 Titik pengambilan sampel tanah

Data primer yang diambil berupa data pertumbuhan tanaman aren yang meliputi:

1. Tinggi tanaman $(\mathrm{m})$, diukur dari permukaan tanah hingga titik tumbuh;

2. Diameter $(\mathrm{cm})$, diukur satu meter dari permukaan tanah;

3. Jumlah tanaman aren yang sehat ditandai dengan penampakan bagian tanaman secara lengkap (daun, cabang dan ranting), batang lurus, warna daun hijau serta terbebas dari serangan hama penyakit serta gulma;

4. Jumlah tanaman aren yang tidak sehat ditandai dengan pertumbuhan tanaman tidak normal, pertumbuhan stagnan yaitu diameter dan tinggi tanaman lebih kecil dari tanaman seumur (Istomo et al. 2013), dan memiliki daun yang berwarna kekuningan.
Analisis data yang digunakan dalam penelitian ini adalah perhitungan nilai persentasi hidup tanaman aren, persentasi nilai kesehatan tanaman aren, dan tinggi tanaman dan diameter tanaman aren yang hidup. Nilai persentase hidup tanaman dihitung menggunakan persamaan (Permenhut 2009):

$$
T=\frac{\sum h i}{\sum N i} \times 100 \%
$$

keterangan:

$\mathrm{T}=$ persen hidup tanaman $(\%)$

$\mathrm{h}_{\mathrm{i}}=$ jumlah tanaman yang hidup pada plot ke-i

$\mathrm{Ni}=$ jumlah tanaman yang ditanam pada plot ke-i

Rata-rata persentase hidup tanaman dihitung dengan persamaan (Permenhut 2009):

$$
R=\sum_{i=1}^{n} T i / n
$$

keterangan:

$\mathrm{R}=$ rata-rata persentase hidup tanaman $(\%)$

$\mathrm{Ti}=$ jumlah persentase hidup tanaman pada plot ke-i

$\mathrm{n}=$ jumlah seluruh plot

Persentase kesehatan tanaman dihitung dengan persamaan (Permenhut 2009) :

$$
K=\frac{\sum r i}{\sum h i} \times 100 \%
$$

Keterangan:

$\mathrm{K}=$ persentase kesehatan tanaman $(\%)$

$\mathrm{ri}=$ jumlah tanaman sehat pada plot ke-i

hi $=$ jumlah tanaman yang hidup pada plot ke $-\mathrm{i}$

Rata-rata persentase kesehatan tanaman dihitung dengan persamaan sebagai berikut (Permenhut 2009):

$$
P=\sum_{i=1}^{n} K i / n
$$

Keterangan:

$\mathrm{P}=$ rata-rata persentase kesehatan tanaman (\%)

$\mathrm{Ki}=$ jumlah persentase kesehatan tanaman pada plot ke-i $\mathrm{n}=$ jumlah seluruh plot

Persamaan untuk menghitung rata-rata tinggi dan diameter tanaman yaitu sebagai berikut:

$$
\bar{d}=\sum_{i=1}^{n} d 1 / n \quad \bar{t}=\sum_{i=1}^{n} t 1 / n
$$

Keterangan:

$\mathrm{d} \quad=$ rata-rata diameter $(\mathrm{m})$

$\mathrm{t} \quad=$ rata-rata tinggi $(\mathrm{m})$

$\mathrm{di}, \mathrm{ti}=$ diameter dan tinggi pohon ke- $\mathrm{i}$

$\mathrm{n} \quad=$ jumlah pohon yang diukur

Analisis deskriptif dilakukan untuk menentukan sifat fisik dan kimia tanah. 


\section{HASIL DAN PEMBAHASAN}

\section{Sifat Fisik dan Kimia Tanah di Lokasi Pengamatan}

Kesuburan suatu lahan dapat digambarkan dengan melihat kondisi fisik, kimia dan kecukupan unsur hara pada tanah, serta keberadaan mikroorganisme seperti fungi mikoriza. Kegiatan penambangan batu bara umumnya dilakukan dengan sistem terbuka (opened peat mining), yang dimulai dengan kegiatan pembukaan lahan, penyingkiran semua lapisan tanah penutup batu bara, dan penimbunan, sehingga mengakibatkan penurunan kesuburan lahan dan perubahan topografi lahan (Setiadi 2009). Oleh karena itu, perlu dilakukan analisis sifat fisik, kimia dan logam berat yang terkandung dalam tanah yang disajikan pada Tabel 1 .

Hasil analisis pada Tabel 1 menunjukkan bahwa tanah yang terdapat pada ke empat titik pengambilan sampel yaitu IPD D6, C3.1, C3.2 dan IPD K, umumnya memiliki tekstur debu yang dominan sehingga masuk pada kelas lempung liat berdebu dibandingkan dengan tanah pada lokasi IPD D2 yang masuk dalam kelas liat. Menurut Sunanto (1993) dan Effendi (2009), tanaman aren sangat cocok pada kondisi tanah yang bertekstur liat dan berpasir, serta berada pada kondisi lahan yang landai, sehingga persen kesehatan tanaman aren di plot IPD D2 hanya berkisar 40,7\% yang tidak sebanding dengan persen tumbuhnya yang $>50 \%$ yaitu $87,1 \%$. Hal tersebut terjadi karena tekstur tanah sangat berpengaruh terhadap permeabilitas, aerasi, bulk density dan porositas tanah (Budiana et al. 2017).

Perbedaan tekstur, bulk density (BD) dan porositas tanah dipengaruhi oleh kondisi lahan, keberadaan vegetasi dan bahan tanah yang digunakan dalam penimbunan pada awal kegiatan reklamasi. Tabel 1 menunjukkan nilai bulk density tanah pada kelima titik pengambilan sampel, tergolong besar. Hardjowigeno (2007) menyatakan nilai bulk density pada tanah mineral umumnya berkisar 1-1,6 $\mathrm{g} / \mathrm{cm}^{3}$. Penurunan nilai BD di lokasi IPD D2 sebesar 52,58\% dengan IPD 6 sebesar $47,00 \%$, mengindikasikan pertumbuhan aren yang baik pada plot IPD D6 yaitu $60 \%$ dengan nilai persen kesehatan $100 \%$ disebabkan oleh perakaran tanaman aren di plot IPD D6 yang berperan dalam menurunkan nilai BD. Bulk density atau bobot isi menggambarkan kepadatan tanah, semakin tinggi nillainya maka akan mengurangi penetrasi akar dalam tanah (Yulina et al. 2018). Kualitas fisika tanah yang menunjang perkembangan akar tanaman, dapat dipertahankan dengan meningkatkan kandungan bahan organik tanah (Hairiah 2000) sehingga terbentuk celah-celah yang mudah ditembus akar (Kusuma et al. 2013). Hal ini sesuai dengan pernyataan Mariana (2006) bahwa bahan organik bersifat porus, dan Wigati et al. (2006) bahwa akar tanaman merupakan partikel perekat tanah, sehingga ketersediannya dalam jumlah banyak dalam tanah, dapat meningkatkan ruang pori di dalam tanah dan menyebabkan bobot isi tanah menjadi berkurang.

Tabel 1 Hasil analisis sifat kimia tanah di lokasi pengambilan sampel di PT Berau Coal

\begin{tabular}{|c|c|c|c|c|c|}
\hline \multirow{2}{*}{ Sifat tanah } & \multicolumn{5}{|c|}{ Lokasi } \\
\hline & IPD D6 & $\mathrm{C} 3.1$ & $\mathrm{C} 3.2$ & IPD D2 & IPD K \\
\hline \multicolumn{6}{|l|}{ Tekstur (\%) } \\
\hline Pasir & 13,78 & 21,68 & 29,36 & 10,49 & 17,38 \\
\hline Debu & 46,78 & 40,72 & 52,47 & 30,34 & 46,78 \\
\hline Liat & 35,84 & 37,60 & 18,17 & 59,17 & 35,84 \\
\hline Bulk density $\left(\mathrm{g} / \mathrm{cm}^{3}\right)$ & 1,26 & 1,39 & 1,24 & 1,40 & 1,38 \\
\hline Porositas (\%) & 52,58 & 47,39 & 53,26 & 47,00 & 48,09 \\
\hline \multicolumn{6}{|l|}{ pH } \\
\hline $\mathrm{H}_{2} \mathrm{O}$ & $4,15 \mathrm{~m}$ & $4,19 \mathrm{~m}$ & $4,46 \mathrm{~m}$ & $4,24 \mathrm{~m}$ & $4,81 \mathrm{~m}$ \\
\hline C-org (\%) & $1,35 \mathrm{r}$ & $1,62 \mathrm{r}$ & $1,22 \mathrm{r}$ & $0,25 \mathrm{sr}$ & $0,89 \mathrm{sr}$ \\
\hline N-Total (\%) & $0,12 \mathrm{r}$ & $0,13 \mathrm{r}$ & $0,13 \mathrm{r}$ & $0,13 \mathrm{r}$ & $0,13 \mathrm{r}$ \\
\hline C/N Ratio & $11,25 \mathrm{~s}$ & $12,46 \mathrm{~s}$ & $9,38 \mathrm{r}$ & $1,92 \mathrm{r}$ & $6,84 \mathrm{r}$ \\
\hline \multicolumn{6}{|l|}{ Kadar P (ppm) } \\
\hline Bray 1 & $1,43 \mathrm{r}$ & $21,12 \mathrm{t}$ & $18,07 \mathrm{~s}$ & $6,48 \mathrm{sr}$ & $137,34 \mathrm{st}$ \\
\hline KTK $\left(\mathrm{cmol}^{(+)} / \mathbf{k g}\right)$ & $15,22 \mathrm{r}$ & $13,83 \mathrm{r}$ & $20,65 \mathrm{~s}$ & $34,01 \mathrm{t}$ & $15,61 \mathrm{st}$ \\
\hline Al $\left(\mathbf{c m o l}^{(+)} / \mathbf{k g}\right)$ & $7,50 \mathrm{sr}$ & $1,56 \mathrm{sr}$ & $1,47 \mathrm{sr}$ & $8,52 \mathrm{sr}$ & $1,23 \mathrm{sr}$ \\
\hline \multicolumn{6}{|l|}{ Logam Berat (ppm) } \\
\hline $\mathrm{Fe}$ & 131,5 & 185,56 & 196,87 & 15,94 & 128,90 \\
\hline $\mathrm{Cu}$ & 3,92 & 3,40 & 2,92 & 1,61 & 2,65 \\
\hline $\mathrm{Zn}$ & 2,66 & 3,39 & 4,20 & 1,76 & 3,93 \\
\hline Mn & 13,52 & 70,70 & 72,31 & 7,42 & 51,84 \\
\hline $\mathrm{Pb}$ & 2,18 & 1,50 & 2,47 & 1,95 & 2,18 \\
\hline
\end{tabular}

Keterangan: sr: sangat rendah, r: rendah, s: sedang, t: tinggi, st: sangat tinggi (perbandingan berdasarkan Pusat Penelitian Tanah 1983). 
Tabel 1 menunjukkan nilai porositas tanah pada ke lima lokasi pengamatan tidak berbeda secara signifikan, namun pada plot C3.1 memiliki nilai porositas yang tinggi yaitu 53,26\%. Menurut Hanafiah (2007) porositas tanah adalah rongga tanah yang berisi air dan udara dan sangat menentukan permeabilitas tanah. Semakin besar porositas tanah, maka semakin cepat pula permeabilitas tanah tersebut sehingga akar tanaman mudah menyerap unsur hara dan air.

Iskandar et al. (2012) mengemukakan bahwa bagian permukaan lahan hasil regrading yang ditutup kembali dengan top soil umumnya memiliki sifat kimia dan fisik yang buruk. Tabel 1 menunjukkan hasil analisis sifat kimia dan kandungan logam berat pada ke lima lokasi pengambilan sampel (IPD D6, C3.1, C3.2, IPD D2 dan IPD K) PT Berau Coal. Jika dibandingkan dengan kriteria sifat kimia tanah dari Pusat Penelitian Tanah (1983), maka $\mathrm{pH}$ tanah dari ke lima lokasi tergolong masam yaitu berkisar dari 4,15- 4,81. Puturuhu et al. (2011) menyatakan bahwa tanaman aren dapat hidup pada $\mathrm{pH}$ tanah masam- sangat masam. Munawar (2011) menyatakan bahwa pada tanah masam ( $\mathrm{pH}$ rendah), unsur $\mathrm{P}$ (phospor) larut akan bereaksi dengan $\mathrm{Al}$ dan Fe dan oksida-oksida hidrus lainnya membentuk senyawa Al-P dan Fe-P yang relatif kurang larut, sehingga $\mathrm{P}$ (Phospor) tidak dapat diserap oleh tanaman. Kadar Ptersedia di kelima lokasi tergolong rendah hingga sangat tinggi yaitu 1,43-137,34 ppm pada lokasi pertambangan. Ketidakmerataan unsur hara terjadi karena perbedaan tanah pucuk yang disebarkan untuk reklamasi, selain itu keberadaan mikroorganisme seperti mikoriza juga memengaruhi kandungan Phospor pada lokasi. pH tanah dapat menjadi faktor penyebab munculnya tanaman stagnan. Besarnya nilai $\mathrm{pH}$ tanah pada IPD D2 tergolong masam (4,24). Kondisi tanah yang masam dapat menghambat pertumbuhan tanaman, antara lain keracunan $\mathrm{Al}$, kekahatan nitrogen $(\mathrm{N})$, Phospor (P), Ca dan Mg (Munawar 2011; Budiana et al. 2017).

Menurut Hakim et al. (1986), masalah lain yang timbul pada tanah asam adalah rendahnya Kapasitas Tukar Kation (KTK) yang menyebabkan menurunnya kemampuan tanah dalam menyerap unsur hara dan melepaskannya untuk diserap oleh akar tumbuhan. Nilai KTK pada lima lokasi pengamatan tergolong rendah hingga sangat tinggi yaitu $13,83-34,01 \mathrm{cmol}^{(+)} / \mathrm{kg}$.

Hasil analisis laboratorium pada Tabel 1 menunjukkan bahwa nilai P-tersedia terkecil berada pada lokasi IPD D6 yaitu 1,43 ppm, dan terbesar pada lokasi reklamasi IPD K yaitu 137, 34\% melebihi nilai P-tersedia pada lokasi yang telah lama di reklamasi. Hal ini diduga karena penambahan unsur $\mathrm{P}$ (Phospor) dalam jumlah besar pada awal kegiatan reklamasi, jumlah bahan organik yang diberikan pada saat awal kegiatan reklamasi, serta keberadaan vegetasi pada lahan reklamasi IPD K. Sebagaimana pada penelitian Hamid et al. (2017) nilai P-tersedia pada lahan yang belum dilakukan penambangan lebih kecil dari nilai $\mathrm{P}$ pada lahan reklamasi tujuh tahun. Nilai $\mathrm{P}$ yang tinggi sangat dipengaruhi oleh kondisi bahan organik yang dimiliki oleh suatu lahan reklamasi dan kombinasi penggunaan pupuk serta bahan organik yang tinggi (Chaubey et al. 2012).

C-org untuk ke lima lokasi terbilang rendah hingga sangat rendah pada lokasi IPD D2 dan IPD K. Menurut Hardjowigeno (1987), C-organik dikategorikan sangat rendah jika kurang dari $1 \%$ dan sangat tinggi jika lebih dari 5\%. Dari kelima lokasi penanaman aren yang diamati, lokasi IPD D2 memiliki persentasi tekstur tanah debu dan liat yang tinggi, C-org yang sangat rendah yaitu $0,25 \%, \mathrm{~N}$ total rendah $0,13 \%$, dan $\mathrm{C} / \mathrm{N}$ ratio yang rendah yaitu 1,92 , keadaan ini mengindikasikan bahwa tanah di lokasi IPD D2 memiliki kesuburan rendah sehingga kesehatan tanaman juga rendah yaitu 40\%, selain pertumbuhan tinggi dan diameter tanaman yang juga lambat.

Performa tanaman juga dipengaruhi oleh unsur hara primer lain yaitu nitrogen $(\mathrm{N})$, yang merupakan bagian dari klorofil yang sangat berperan dalam fotosintesis. Kandungan unsur $\mathrm{N}$ pada ke lima lokasi tergolong rendah yaitu berkisar antara 0,12-0,13 \%. Menurut Nyakpa et al. (1988), lapisan olah tanah umumnya mengandung $0,02-0,40 \% \mathrm{~N}$, yang ditunjukkan oleh kondisi daun tanaman aren yang menguning dan kecoklatan seperti terbakar.

Hasil analisis kimia tanah pada Tabel 1 menunjukkan tingginya nilai Fe pada lokasi C3.2 yaitu sebesar $196,87 \%$ sehingga terindikasi terjadinya keracunan pirit. Mineral pirit banyak dijumpai pada tambang batu bara. Banyaknya kandungan pirit dalam tanah dapat menurunkan $\mathrm{pH}$ tanah dan menjadikan tanah menjadi masam sehingga dapat meningkatkan kelarutan logam-logam berat yang berpotensi meracuni tanaman. Keberadaan pirit yang tinggi pada tanah dapat menyebabkan tanaman tumbuh kerdil. Hal ini diduga menjadi penyebab banyaknya tanaman kerdil dan tidak sehat di lokasi C3.2 dengan rata-rata tinggi yang jauh berbeda dengan tanaman di sekitarnya yang sehat. Meskipun tanaman aren termasuk ke dalam jenis tanaman yang dapat tumbuh pada areal yang miskin hara atau kritis, namun pada kondisi yang ekstrim, tanaman aren tidak dapat tumbuh dengan optimal.

Berdasarkan perbandingan hasil analisis logam berat pada tanah di kelima lokasi pengamatan dengan ambang batas logam berat pada tanah yang dikeluarkan oleh Ministry of State of Population and Environment of Indonesia and Dalhousie University (1992) dapat terlihat bahwa logam berat pada ke lima lokasi pengamatan masing tergolong tidak meracuni. Kadar $\mathrm{Pb}$ yang ditoleransikan dalam jaringan tanaman adalah $10 \mathrm{ppm}$ (Sitorus et al. 2008) dan 100 ppm dalam tanah. Kadar yang ditoleransi untuk tanaman berbeda menurut bagian tanaman, dan paling tinggi pada bagian akar, semakin ke bagian atas tanaman, akan semakin rendah. Sebagai contoh, akar tanaman padi memiliki kandungan $\mathrm{Pb}$ 17,33 ppm, di batang 3,67 ppm dan di beras 0,00 ppm. Bagi tanaman aren dengan ukuran tanaman lebih besar dari 
tanaman padi, maka kandungan $\mathrm{Pb}$ di lima lokasi tersebut tidak membahayakan tanaman.

\section{Pertumbuhaan Tanaman Aren (A. pinnata)}

a. Persentasi tumbuh dan kesehatan tanaman aren (A. pinnata)

Tabel 2 menunjukkan rekapitulasi persentase hidup dan kesehatan tanaman, pada tanaman yang tumbuh di lahan revegetasi aren PT Berau Coal Site Binungan I. Persen tumbuh pada plot IPD D6, plot C3.2, plot IPD K dan plot IPD D2 berkisar antara 60-87,1\% dan pada plot C3.1 persentase tumbuh sangat rendah yaitu 19,35\%.

Hasil perhitungan persen tumbuh dan persen kesehatan tanaman menunjukkan bahwa plot IPD D2 memiliki persen tumbuh tertinggi dari kelima plot yang diukur dan plot C3.1 memiliki nilai persen tumbuh tanaman terendah, yaitu sebesar 19,35\% (Tabel 2). Hal ini karena pada plot C3.1 terdapat banyak tanaman yang sudah mati dan dirusak oleh babi. Babi merupakan hama pada tanaman aren yang memakan umbut atau bakal daun muda aren yang lembut dan terasa manis, sehingga menyebabkan pertumbuhan tanaman aren menjadi terhambat. Selain itu lokasi plot C3.1 dan C3.2 juga dekat dengan rawa atau kubangan air sehingga menjadi tempat yang cocok bagi babi untuk mencari pakan. Habitat babi adalah hutan primer, hutan sekunder, semak belukar, padang alang-alang, dan pertanaman atau perkebunan yang tidak terurus. Habitat yang dipilih terutama berhubungan dengan sumberdaya, yaitu ketersediaan pakan dan dekat dengan sumber air sebagai tempat untuk berkubang. Babi selalu melakukan aktivitas berkubang setiap hari dan relatif tidak tahan terhadap panas matahari (Priyambodo 1990). Berbeda halnya dengan aren pada plot IPD D2 yang memiliki persentase tumbuh tertinggi yaitu $87,1 \%$ karena tidak ada gangguan dari hama babi.

Nilai rata-rata persen kesehatan tanaman di lima lokasi pengamatan (IPD D6, C3.1, C3.2, IPD D2, IPD K) sebesar $59,40 \%$ yang menunjukkan kondisi kesehatan yang kurang baik. Nilai persentase kesehatan tanaman untuk lokasi IPD D2 sebesar 40,7\%. Tanaman pionir seperti sengon (Paracerianthes falcataria), johar (Cassia siamea) dan jabon (Anthocephallus cadamba) yang tumbuh di plot ini masih berukuran kecil sehingga tidak dapat menaungi tanaman aren. Intensitas naungan 0\% menyebabkan intensitas cahaya matahari yang diperoleh tanaman aren sangat besar yaitu sebesar \pm 67.201 lux. Tanaman aren merupakan salah satu tanaman semi toleran atau yang memerlukan naungan saat awal pertumbuhan. Menurut Mujahidin et al. (2003) dan Furqoni (2014), tanaman aren yang berumur kurang dari 2 tahun yang ditanam di lahan terbuka, harus diberikan naungan agar tanaman tidak kering dan mati.

Plot IPD D6 dan C3.1 merupakan plot dengan nilai persen kesehatan tanaman tertinggi yaitu $100 \%$ dan plot C3.2 merupakan plot dengan persen kesehatan terendah dengan nilai 26,32\%. Kesehatan tanaman dapat ditentukan oleh ketahanan tanaman terhadap serangan hama penyakit. Pada kelima lokasi pengamatan ditemukan banyak daun terserang hama dan penyakit, ditandai dengan banyaknya daun tanaman yang menguning, terdapat bintik kehitaman, bekas gerekan pada daun seperti terpotong-potong, serta daun berwarna kecoklatan seperti terbakar. Hasil ini sejalan dengan penelitian Effendi (2010) yang menemukan bahwa hama penggerek daun muda Artona sp. merupakan hama yang banyak menyerang daun tanaman aren dan kelapa, ditandai dengan penampakan daun seperti terpotongpotong. Penyakit pada tanaman aren yang menyebabkan bercak dan kuning pada daun aren di persemaian disebabkan oleh Pestalotia sp. dan Helmiathosporus sp. (Lasut 2012).

\section{b. Diameter, tinggi dan jumlah daun tanaman aren (A. pinnata)}

Kualitas pertumbuhan suatu jenis tanaman dapat diduga dengan melihat indikator morfologi tanaman yaitu pertambahan tinggi, diameter dan jumlah daun (Tamin 2016). Pertumbuhan vertikal atau tinggi dan pertumbuhan horizontal atau diameter tanaman dipengaruhi oleh kemampuan tanaman dalam berinteraksi dengan faktor lingkungan dan kemampuan memperoleh makanan dan ruang tumbuh. Interaksi faktor tersebut dapat memengaruhi pertumbuhan dan ukuran batang yang berbeda pada setiap jenis atau kelompok tanaman tertentu (Husch et al. 1972; Huang et al. 2000). Hasil rata-rata pengukuran diameter dan tinggi tanaman aren disajikan pada Tabel 3.

Tabel 2 Nilai daya tumbuh tanaman aren (A. pinnata) di PT Berau Coal

\begin{tabular}{lcccccc}
\hline \multirow{2}{*}{ Data } & \multicolumn{5}{c}{ Plot } \\
\cline { 2 - 6 } & $\begin{array}{c}\text { IPD D6 } \\
(2005)^{*}\end{array}$ & $\begin{array}{c}\text { C3.1 } \\
(2016)^{*}\end{array}$ & $\begin{array}{c}\text { C3.2 } \\
(2016)^{*}\end{array}$ & $\begin{array}{c}\text { IPD D2 } \\
(2018)^{*}\end{array}$ & $\begin{array}{c}\text { IPD K } \\
(2015)^{*}\end{array}$ & Rata-rata \\
\hline Persen tumbuh (\%) & 60 & 19,35 & 61,29 & 87,1 & 64,52 & 58,45 \\
\hline Persen kesehatan tanaman (\%) & 100 & 100 & 26,32 & 40,7 & 30 & 59,40 \\
\hline
\end{tabular}

Ket: * Tahun tanam aren 
Tabel 3 Pertumbuhan diameter, tinggi dan jumlah daun tanaman aren (Arenga pinnata) di PT Berau Coal

\begin{tabular}{lccccc}
\hline Parameter & \multicolumn{5}{c}{ Plot } \\
\cline { 2 - 6 } & IPD D6 & C3.1 & C3.2 & IPD D2 & IPD K \\
& $(2005)^{*}$ & $(2016)^{*}$ & $(2016)^{*}$ & $(2018)^{*}$ & $(2015)^{*}$ \\
\hline Diameter (cm) & $48,2 \pm 0,11$ & $11,2 \pm 0,04$ & $11 \pm 0,03$ & $5,8 \pm 0,016$ & $6 \pm 0,11$ \\
Tinggi (m) & $4,35 \pm 1,78$ & $2,14 \pm 0,50$ & $1,68 \pm 0,79$ & $0,92 \pm 0,28$ & $1,2 \pm 0,60$ \\
JDH & $10,75 \pm 2,78$ & $4,50 \pm 0,83$ & $2,89 \pm 1,32$ & $1,70 \pm 1,27$ & $3,40 \pm 1,31$ \\
JDS & $0 \pm 0$ & $0 \pm 0$ & $1,38 \pm 1,51$ & $1,75 \pm 0,77$ & $1,22 \pm 1,06$ \\
\hline
\end{tabular}

Ket : JDH (Jumlah daun hijau), JDS (Jumlah daun sakit); * Tahun tanam aren

Tabel 3 menunjukkan perbedaan rata-rata diameter, tinggi, jumlah daun hijau dan jumlah daun sakit yang signifikan antara kelima lokasi pengambilan sampel dipengaruhi oleh umur reklamasi dengan tanaman aren (Arenga pinnata) dan kondisi tanah setiap lokasi. Berdasarkan hasil pengamatan yang disajikan pada Tabel 3, pertumbuhan tanaman aren di lokasi IPD D6 yang berumur 14 tahun dapat dikatakan baik. Hal ini sesuai dengan Permentan Nomor 133 Tahun 2013 yang menetapkan bahwa tanaman aren yang ideal untuk umur tanaman di atas 5 tahun memiliki tinggi rata-rata 3-4 m dan diameter rata-rata $40-50 \mathrm{~cm}$. Hasil pengamatan pertumbuhan tanaman aren di lima lokasi juga menunjukkan kemampuan pertumbuhan diameter dan tinggi yang baik pada plot IPD D6, IPD K, C3.1 dan C3.2. Hal tersebut karena pada keempat lokasi ini terdapat naungan yang cukup berupa tanaman jenis johar (Cassie siamea), sengon (Paraserianthes falcataria), Eucalypthus sp, jabon (Antocephalus cadamba) dan tanaman lainnya serta terdapat genangan air. Menurut Permentan Nomor 133 Tahun 2013 tanaman aren dapat tumbuh dengan baik di daerah yang dekat dengan aliran sungai dan memiliki kelembaban tanah dan ketersediaan air yang tinggi. Furqoni (2014) mengemukakan bahwa tanaman aren merupakan tanaman semi toleran yang memerlukan naungan untuk pertumbuhannya.

Berdasarkan pengamatan di lokasi plot IPD D6 yang merupakan tanaman aren berusia $>10$ tahun, ditemukan tiga pohon yang telah memproduksi bunga jantan dan betina. Pada tanaman dewasa, produksi bunga jantan dan betina menjadi buruk disebabkan karena kurangnya kandungan unsur hara di tanah khususnya unsur hara P. Seperti diketahui, unsur hara P merupakan unsur hara essensial yang berfungsi dalam merangsang pembungaan dan pembuahan sehingga jika tersedia dalam jumlah sedikit, bunga akan cepat rontok dan buah akan mengalami perkembangan yang tidak sempurna (Hanafiah 2007). Menurut Nurwanto et al. (2017), faktor lain yang sangat memengaruhi kerontokan bunga adalah unsur hara kalium yng dibutuhkan dalam penutupan dan pembukaan stomata serta dalam akumulasi dan translokasi karbohidrat.

Banyaknya jumlah optimal dari pelepah daun membentuk karbohidrat dalam proses fotosintesis dan meningkatkan proses evapotranspirasi (Arsyad et al. 2012), namun kondisi daun pada pohon aren di lokasi pengamatan terlihat kurang produktif karena daun tanaman tidak berwarna hijau segar, bahkan banyak yang berwarna kekuningan, berdebu dan kotor, kering dan kusam serta beberapa pelepah daun terlihat berjamur. Hal ini dapat terjadi karena tertutupnya permukaan daun aren oleh debu akibat aktivitas pertambangan serta minimnya unsur hara dalam tanah, seperti kekurangan unsur nitrogen yang diindikasikan oleh warna awal daun yang agak kuning, lalu kekuningan, dan kemudian berwarna merah kecoklatan.

\section{Hubungan sifat fisika dan kimia tanah terhadap pertumbuhan aren (A.pinnata)}

Hubungan sifat fisika dan kimia tanah dengan persen hidup aren, persen kesehatan aren, diameter, tinggi dan jumlah daun aren digambarkan dengan korelasi pearson yang dapat dilihat pada Tabel 4. Berdasarkan Tabel 4 tersebut, diketahui bahwa persen hidup, persen sehat, diameter, dan tinggi tanaman aren dipengaruhi oleh beberapa faktor kimia fisik tanah. C-organik berpengaruh nyata dengan persen hidup aren $(\mathrm{p}=0,05 \leq 0,05)$ dengan nilai korelasi $(r=-0,878)$. C-organik dapat menggambarkan kandungan bahan organik di tanah yang menggambarkan pori-pori tanah.

Banyaknya pori-pori tanah yang terbentuk membuat proses pertukaran $\mathrm{O}^{2}$ dan $\mathrm{CO}^{2}$ dalam tanah menjadi lebih baik sehingga kebutuhan air dan oksigen dalam tanah dapat terjaga dengan baik (Erizina et al. 2018) dan berdampak pada peningkatan pertumbuhan dan kesehatan tanaman. Berbeda halnya dengan diameter tanaman aren $(p=0,001 \leq 0,001)$ yang berpengaruh sangat nyata dengan kadar $\mathrm{N}$ yang dengan nilai korelasi $(\mathrm{r}=$ $-0,989)$ dan berpengaruh nyata dengan tinggi tanaman aren $(\mathrm{p}=0,018 \leq 0,05)$ dengan nilai korelasi $(\mathrm{r}=-0,940)$. Tanaman yang tumbuh pada tanah yang kekurangan $\mathrm{N}$ akan menunjukan gejala kerdil dan pertumbuhan akar yang terbatas karena terjadi penurunan kemmapuan pembelahan, perpanjangan dan diferensiasi sel pada tanaman. 
Tabel 4 Hasil analisis korelasi antara sifat fisika dan kimia tanah dengan pertumbuhan tanaman aren (A. pinnata)

\begin{tabular}{|c|c|c|c|c|}
\hline \multirow{2}{*}{ Sifat fisik dan kimia tanah } & \multicolumn{4}{|c|}{ Nilai korelasi (r) } \\
\hline & Persen hidup (\%) & Persen sehat $(\%)$ & $\mathrm{D}$ & $\mathrm{T}$ \\
\hline Bulk density (BD) & $-0,053$ & $-0,018$ & $-0,597$ & $-0,579$ \\
\hline Porositas & $+0,060$ & $+0,007$ & $+0,601$ & $+0,580$ \\
\hline $\mathrm{pH}$ & $+0,220$ & $-0,726$ & $-0,496$ & $-0,525$ \\
\hline C-organik & $-0878 *$ & $+0,626$ & $+0,418$ & $+0,598$ \\
\hline $\mathrm{N}$ & $-0,035$ & $-0,606$ & $-0,989 * *$ & $-0,940 *$ \\
\hline $\mathrm{C} / \mathrm{N}$ ratio & $-0,846$ & $+0,663$ & $+0,497$ & $+0,667$ \\
\hline $\mathrm{P}$ & $+0,044$ & $-0,452$ & $-0,409$ & $-0,411$ \\
\hline KTK & $+0,749$ & $-0,481$ & $-0,379$ & $-0,527$ \\
\hline $\mathrm{Al}$ & $+0,581$ & $+0,228$ & $+0,455$ & $+0,304$ \\
\hline $\mathrm{Fe}$ & $-0,749$ & $+0,211$ & $+0,120$ & $+0,290$ \\
\hline $\mathrm{Cu}$ & $-0,663$ & $+0,711$ & $+0,738$ & $+0,856$ \\
\hline $\mathrm{Pb}$ & $+0,588$ & $-0,608$ & $+0,171$ & $+0,049$ \\
\hline
\end{tabular}

Ket: $* *=$ Berpengaruh sangat nyata pada $(\mathrm{P} \leq 0,001),{ }^{*}=$ berpengaruh nyata pada $(0,001<\mathrm{P} \leq 0,05)$

\section{SIMPULAN}

Revegetasi lahan pasca tambang dengan tanaman aren (A. pinnata) di PT Berau Coal Kalimantan Timur memiliki nilai persen tumbuh tanaman aren $58,45 \%$ dan persen kesehatan 59,40\%. Faktor-faktor yang memengaruhi pertumbuhan dan kesehatan tanaman aren di lahan reklamasi PT Berau Coal yaitu: kesuburan tanah, kepadatan tanah, intensitas naungan, dan hama penyakit.

\section{DAFTAR PUSTAKA}

Agus C, Pradipa E, Wulandari D, Supriyo H, Saridi, Herika D. 2014. Peran revegetasi tanah pada lahan rehabilitasi tambang batubara di daerah tropika. Jurnal Manusia dan Lingkungan. 21(1):60-66.

Arsyad AR, Junedi H, Yulfita F. 2012. Pemupukan kelapa sawit berdasarkan potensi produksi untuk meningkatkan hasil tandan buah segar (TBS) pada lahan marginal kumpeh. Jurnal penelitian Universitas Jambi. 14(1):29-36.

Budiana IGE, Jumani, Biantary MP. 2017. Evaluasi tingkat keberhasilan revegetasi lahan tambang batubara di PT Kitadin Site Embalut Kabupaten Kutai Kartanegara Kalimantan Timur. Jurnal AGRIFOR. 16(2):195-207.

Chaubey OP, Bohre P, Singhal PK. 2012. Impact of bioreclamation of coal mine spoil on nutritional and microbial characteristics. International Journal of Bio-Science and Bio-Technology. 4(3):69-80.

[Disbun Kaltim] Dinas Perkebunan Provinsi Kalimantan Timur. 2018. Data Luas dan Produksi Tanaman Aren. Samarinda: Dinas Perkebunan Provinsi Kalimantan Timur.

Effendi SD. 2009. Aren, sumber energi alternatif. Warta Penelitian dan Pengembangan Pertanian. 31(2):1-3.

Effendi SD. 2010. Prospek Pengembangan Tanaman Aren (Arenga piñata Merr) Mendukung Kebutuhan
Bioethanol Indonesia. Bogor: Pusat Penelitian dan Pengembangan Perkebunan.

Erizina E, Pamoengkas P, Darwo. 2018. Hubungan sifat fisik dan kimia tanah dengan pertumbuhan meranti merah di KHDTK Haurbentes. Jurnal Pengelolaan SDA dan Lingk. 8(2):216-222.

Furqoni H. 2014. Karakterisasi benih dan perkecambahan aren (Arenga pinnata (Wurmb.) Merr.) serta respon pertumbuhan bibit terhadap intensitas naungan [Tesis]. Bogor: Institut Pertanian Bogor.

Forest Watch Indonesia. 2011. Potret Keadaan Hutan Indonesia. Bogor: Forest Watch Indonesia.

Hadjowigwno. 2007. Ilmu Tanah. Jakarta: Mediyatama Sarana Perkasa.

Hairiah K. 2000. Pengelolaan Tanah Masam secara Biologi. Bogor: International Centre for Research in Agroforestry.

Hakim N, Nyakpa MY, Lubis AM, Nugroho SG, Diha MA, Hong GB, Bailey HH. 1986. Dasar-Dasar Ilmu Tanah. Lampung: Universitas Lampung.

Hamid I, Priatna SJ, Hermawan A. 2017. Karakteristik beberapa sifat fisika dan kimia tanah pada lahan bekas tambang timah. Jurnal Penelitian Sains. 19(1):23-31.

Hanafiah KA. 2007. Dasar-dasar Ilmu Tanah. Jakarta: PT. Raja Grafindo Persada.

Harahap DE. 2017. Kajian produktivitas tanaman aren berdasarkan sifat morfologi tanaman pada skuen tinggi tempat di Kabupaten Tapanuli Selatan. Jurnal Pertanian Tropik. 4(2):161-170.

Hardjowigeno S. 2007. Ilmu Tanah. Jakarta: Penerbit Akademika Pressindo.

Herlina A, Handayani HE, Iskandar H. 2014. Pengaruh Fly Ash Dan Kapur Tohor Pada Netralisasi Air Asam Tambang Terhadap Kualitas Air Asam Tambang (Ph, Fe \& Mn) di IUP Tambang Air Laya PT. Bukit Asam (Persero) Tbk. J Ilmu Teknik Univ Sriwijaya. 2(2):18. 
Huang S, Price D, Titus SJ. 2000. Development of ecoregion-based height-diameter models for white spruce in boreal forests. Forest Ecology and Management. 129:125-141.

Husch B, Miller CI, Beers TW. 1972. Forest Mensuration. Second Edition. New York: The Ronald Press Company.

Iskandar, Suwardi, Suryaningtyas DT. 2012. Reklamasi lahan-lahan bekas tambang: beberapa permasalahan terkait sifat-sifat tanah dan solusinya. Seminar Nasional Teknologi Pemupukan dan Pemulihan Lahan Terdegradasi; Bogor, Indonesia. Bogor: Pusat Studi Reklamasi Tambang LPPM IPB.

Istomo, Setiadi Y, Putri AN. 2013. Evaluasi keberhasilan tanaman hasil revegetasi di lahan pasca tambang batubara Site Lati PT. Berau Coal Kalimantan Timur. Jurnal Silvikultur Tropika. 4(2):77-8.

Kementerian Energi dan Sumber Daya Mineral. 2019. Realisasi Produksi dan Penjualan Batubara Tahun 2016-2019 (terhubung berkala) https:// modi. minerba. esdm. go. id/pimpinan/produksiPenjualan?t=2019 . Dikutip [1 januari 2020].

Kumar BM. 2013. Mining waste contaminated lands: an uphill battle for improving crop. Journal of Degraded and Mining Lands Management. 1(1):43- 50.

Kurniawan AR, Surono W. 2013. Model reklamasi tambang rakyat berwawasan lingkungan: Tinjauan atas reklamasi lahan bekas tambang Batu Apung Ijobalit, Kabupaten Lombok Timur, Provinsi Nusa Tenggara Barat. J Teknologi Minerba. 9(3): 165 174.

Kusuma AH, M Izzati, E Saptiningsih. 2013. Pengaruh penambahan arang dan abu sekam dengan proporsi yang berbeda terhadap permeabilitas dan porositas tanah liat serta pertumbuhan kacang hijau (Vigna radiata L). Buletin Anatomi dan Fisiologi. 21(1):1-9.

Lasut MT. 2012. Budidaya yang Baik Aren (Arenga pinnata (Wurmb) Merr.) [modul]. Manado: Universitas Sam Ratulangi dan Universitas Texas A \& M.

Mariana H. 2006. Pengaruh kompos ampas tapioka dan pemberian air terhadap ketersediaan air dan pertumbuhan tanaman sawi (Brassica juncea L.) pada Entisol Wajak, Malang [skripsi]. Malang: Universitas Brawijaya.

Mariati R. 2013. Potensi Produksi dan Prospek Pengembangan Tanaman Aren (Arenga Pinnata MERR) di Kalimantan Timur. J AGRIFOR. 7(2): 196-205.

Ministry of State for Population and Environment Republic of Indonesia and Dalhousie University Canada. 1992. Environmental Management in Indonesia. Report on Soil Quality Standards for Indonesia (interim report). (Tidak dipublikasikan).

Mujahidin, Sutrisno, Latifah D, Handayani T, Fijridianto IA. 2003. Aren Budi Daya dan Prospeknya. Bogor: Pusat Konservasi Tumbuhan Kebun Raya Bogor.
Munawar A. 2011. Kesuburan Tanah dan Nutrisi Tanaman.Bogor: PT Penerbit IPB Press.

Nanggara SG, Barri MF, Rosalina L, Apriani I, Oktaviani AR, Pay P, Rahmawati I. 2018. Silang Sengkarut Pengelolaan Hutan dan Lahan di Indonesia. Bogor: Forest Watch Indonesia.

Nurwanto A, Soedradjad R, Sulistiyaningsih N. 2017. Aplikasi berbagai dosis pupuk kalium dan kompos terhadap produksi tanaman cabai rawit (Capsicum frutescens L). Jurnal Agritop. 15(2):181-193.

Nyakpa MY, Lubis AM, Pulung MA, Amrah AG, Munawar, Hong GB, Hakim N. 1988. Kesuburan Tanah. Lampung: Unila.

Priyambodo S. 1990. Pengendalian Vertebrata Hama Selain Tikus. Bogor: Institut Pertanian Bogor.

Pusat Penelitian Tanah. 1983. Jenis dan Macam Tanah di Indonesia bagi Keperluan Survey dan Pemetaan Tanah Daerah Transmigrasi. Bogor: PPT.

Puspanti A. 2013. Kajian fitoremediasi sebagai salah satu pendukung kegiatan pengelolaan lahan pasca penambangan batubara. Dalam: Reklamasi Lahan Pasca Tambang: Aspek Kebijakan, Konservasi dan Teknologi. Prosiding seminar hasil-hasil penelitian. Balikpapan: Balai Penelitian Teknologi Konservasi Sumberdaya Alam. hal:149-155.

Puturuhu F, Riry J, Ngingi AJ. 2011. kondisi fisik lahan tanaman aren (Arenga pinnata L.) di Desa Tuhaha Kecamatan Saparua Kabupaten Maluku Tengah. J Budidaya Pertanian. 7(2):94-99.

Republik Indonesia. 2013. Peraturan Menteri Pertanian Nomor 133 Tahun 2013 tentang Pedoman Budidaya Aren (Arenga pinnata MERR) yang Baik.

Republik Indonesia. 2009. Peraturan Menteri Kehutanan Nomor P.60 Tahun 2009 tentang Pedoman Penilaian Keberhasilan Reklamasi hutan.

Republik Indonesia. Peraturan Menteri Kehutanan Nomor P.4 Tahun 2011 tentang Pedoman Reklamasi Hutan.

Republik Indonesia. 2018. Peraturan Menteri Energi dan Sumber Daya Mineral Nomor 26 Tahun 2018 tentang Pelaksanaan Kaidah Pertambangan yang Baik dan Pengawasan Pertambangan Mineral dan Batubara.

Setiadi Y. 2009. Revegetasi lahan pasca tambang. Dalam: Reclamation \& Forest Land Rehabilitation After Mining and Oil \& Gas Operation. Green Earth Trainer Bahan Pelatihan. Bogor: 20 - 22 Maret 2009.

Sitorus SRP, Kusumastuti E, Badri LN. 2008. Karakteristik dan teknik rehabilitasi lahan pasca penambangan timah. Jurnal Tanah dan Iklim. 27: 5774.

Sunanto H. 1993. Aren (Budidaya dan Multigunanya). Yogyakarta: Kanisius.

Tamin RP. 2016. Pertumbuhan semai jabon (Antocephalus cadamba Roxb Miq) pada media pasca penambangan batubara yang diperkaya fungi mikoriza arbuskula, limbah batubara dan pupuk NPK. Jurnal Penelitian Universitas Jambi Seri Sains. 18(1):33-43. 
Widyati E. 2009. Kajian fitoremediasi sebagai salah satu upaya menurunkan akumulasi logam akibat air asam tambang pada lahan bekas tambang batubara. Jurnal Tekno Hutan Tanaman. 2(2):67-75.

Wigati ES, Syukur A, Bambang DK. 2006. Pengaruh takaran bahan organik dan tingkat kelengasan tanah terhadap serapan fosfor oleh kacang tunggak di tanah pasir pantai. Jurnal Ilmu Tanah dan Lingkungan. $6(2): 52-58$.

Yulina H, Devnita R, Harryanto R. 2018. Respon air tersedian dan bobo isi tanah pada tanaman jagung manis dan brokoli terhadap kombinasi terak baja dan bokashi sekam padi pada Andisol, Lembang. Jurnal Agrikultura. 29(2): 66-72. 